\title{
GAMBARAN KECEMASAN PASIEN MENGGUNAKAN TERAPI MUSIK KLASIK PADA PROSEDUR EKSTRAKSI GIGI DI RSGM PSPDG-FK UNSRAT
}

\author{
${ }^{1}$ Meliana A. Mantiri \\ ${ }^{2}$ Hendri Opod \\ ${ }^{3}$ Wulan G. Parengkuan \\ ${ }^{1}$ Kandidat Skripsi Program Studi Pendidikan Dokter Gigi Fakultas Kedokteran \\ ${ }^{2}$ Bagian Psikologi Fakultas Kedokteran \\ ${ }^{3}$ Program Studi Pendidikan Dokter Gigi Fakultas Kedokteran \\ Universitas Sam Ratulangi Manado \\ Email: tasyamantiri09@gmail.com
}

\begin{abstract}
Tooth extraction is a complicated procedure, especially if there are additional treatment considerations due to the high risk patients. Anxiety can make the patient cannot cooperate thus inhibit the performance of dentists during dental extraction procedures. Anxiety can be reduced by using distraction techniques such as classical music. This study aimed to obtain an overview of the patient's anxiety using classical music therapy during a tooth extraction procedure in RSGM PSPDG-FK Unsrat. This was a descriptive study with a cross sectional design using the total sampling method. Samples were 40 adults aged 17-65 years consisting of 21 people who had undergone dental extraction and 19 people who had not undergone dental extraction. Physical examination and Visual Analogue Scale (VAS) were performed before and after the classical music therapy. Based on physical examination decreased anxiety was found in $36.83 \%$ of the group who had never undergone a tooth extraction and $11.11 \%$ of the group who had undergone a tooth extraction. Based on VAS, of the group who had never undergone a tooth extraction 26.32\% patients looked slight anxious, $5.26 \%$ looked unpleasant; no patients belonged to the sad category. Of the group who had undergone tooth extraction 9.52\% of patients looked slight anxious. Conclusion: Anxiety of patients who were undergoing dental extraction decreased after classical music therapy performed.
\end{abstract}

Keywords: tooth extraction, anxiety, visual analogue scale, classical music therapy

\begin{abstract}
Abstrak: Prosedur ekstraksi gigi merupakan prosedur yang rumit, terlebih lagi bila ada pertimbangan perawatan tambahan karena adanya pasien dengan resiko tinggi. Kecemasan dapat membuat pasien tidak bisa bekerjasama sehingga menghambat kinerja dokter gigi dalam melakukan prosedur ekstraksi gigi. Kecemasan dapat dikurangi melalui teknik distraksi yang efektif seperti musik klasik. Penelitian ini bertujuan untuk melihat gambaran kecemasan pasien menggunakan terapi musik klasik pada prosedur ekstraksi gigi di RSGM PSPDG-FK Unsrat. Jenis penelitian deskriptif dengan rancangan potong lintang menggunakan metode pengambilan sampel total. Jumlah sampel 40 orang dewasa berusia 17-65 tahun terdiri dari 21 orang pernah dan 19 orang belum pernah menjalani prosedur ekstraksi gigi sebelumnya. Data diambil berdasarkan pemeriksaan fisik dan Visual Analogue Scale (VAS) sebelum dan sesudah mendapat terapi musik klasik. Berdasarkan pemeriksaan fisik pada kelompok yang belum pernah menjalani prosedur ekstraksi gigi terjadi penurunan kecemasan sejumlah $36,83 \%$ pasien dan yang sudah pernah menjalani prosedur ekstraksi gigi sejumlah $11,11 \%$ pasien. Berdasarkan VAS pada pasien yang belum pernah menjalani prosedur ekstraksi gigi sejumlah 26,32\% pasien kategori sedikit cemas, 5,26\% pasien kategori tidak menyenangkan,
\end{abstract}


dan tidak ada pasien pada kategori menyedihkan. Pada yang pernah menjalani prosedur ekstraksi gigi sejumlah 9,52\% pasien kategori sedikit cemas. Simpulan: Kecemasan pasien yang akan menjalani ekstraksi gigi mengalami penurunan setelah mendapat terapi musik klasik.

Kata kunci: ekstraksi gigi, kecemasan, visual analogue scale, terapi musik klasik

Data dari Riset Kesehatan Dasar (RISKESDAS) tahun 2013tentang persentase penduduk Indonesia yang mempunyai masalah gigi dan mulut sebesar $25,9 \%$, dan $31,1 \%$ yang menerima perawatan dan pengobatan dari tenaga medis gigi (perawat gigi, dokter gigi, atau dokter gigi spesialis). Persentase khusus untuk daerah Sulawesi Utara yang mempunyai masalah gigi dan mulut sebesar $31,6 \%$, dan yang menerima perawatan dan pengobatan dari tenaga medis gigi sebesar $25,1 \%$. $^{1}$

Ekstraksi gigi merupakan tindakan sehari-hari yang dilakukan oleh dokter gigi dengan tindakan pencabutan satu gigi utuh maupun akar gigi dalam soket dari tulang alveolar. Kecemasan paling sering ditemukan pada pasien-pasien yang mau melakukan pencabutan gigi. Perasaan cemas ini selalu ada dengan derajat dan manifestasi yang berbeda-beda. ${ }^{2}$

Kecemasan pada prosedur ekstraksi gigi sering disebabkan oleh penggunaan benda-benda tajam seperti jarum, elevator (bein) dan tang, yang dimasukkan secara berurutan maupun bergantian ke dalam mulut. Masalah yang sangat serius bisa terjadi bila kecemasan membuat pasien tidak bisa bekerjasama sehingga menghambat kinerja dokter gigi dalam melakukan prosedur ekstraksi gigi. ${ }^{3}$

Kecemasan yang terjadi pada pasien dapat dikurangi melalui teknik distraksi yang merupakan teknik dengan cara mengalihkan perhatian kepada sesuatu yang lain sehingga kesadaran terhadap kecemasan berkurang. Salah satu teknik distraksi yang efektif adalah musik karena terbukti menunjukkan efek yaitu mengurangi kecemasan. ${ }^{3-6}$ Campbell membuktikan bahwa mendengarkan musik klasik saat perawatan sangat efektif mempengaruhi denyut jantung, denyut nadi dan tekanan darah. ${ }^{5}$

Hasil penelitian yang dilakukan Tangkere $^{3}$ tentang gambaran kecemasan pasien saat menjalani prosedur ekstraksi gigi sambil mendengarkan musik Mozart di Puskesmas Tuminting, dikemukakan bahwa dari sampel 30 orang dewasa berusia 17-65 tahun yang terdiri dari 18 orang pernah dan 12 orang belum pernah menjalani prosedur ekstraksi gigi sebelumnya, terjadi penurunan kecemasan sejumlah $91,67 \%$ pasien pada pengukuran tekanan darah, nadi, respirasi dan Visual Analogue Scale (VAS) yaitu suatu alat ukur untuk menilai fisiologis pasien terhadap kecemasan atau rasa sakit yang ditimbulkan oleh kecemasan.

Berdasarkan survei awal di RSGM PSPDG-FK Unsrat, ditemukan beberapa orang dewasa merasa cemas sesaat sebelum tindakan ekstraksi gigi dan selama prosedur ekstraksi gigi dilakukan. Selain itu di RSGM PSDG-FK Unsrat juga belum pernah dilakukan penelitian sebelumnya. Berdasarkan latar belakang tersebut, maka penulis tertarik untuk melakukan penelitian tentang gambaran kecemasan pasien menggunakan terapi musik klasik pada prosedur ekstraksi gigi di RSGM PSPDGFK Unsrat.

\section{METODE PENELITIAN}

Penelitian ini adalah deskriptif dengan rancangan cross-sectional dilakukan pada selang bulang Agustus-September 2015. Populasi pada penelitian ini yaitu pasien yang menjalani tindakan ekstraksi gigi di RSGM PSPDG-FK Unsrat dan memenuhi kriteria untuk dijadikan sampel. Metode pengambilan sampel adalah total sampling dengan jumlah sampel 40 orang.

Data penelitian diambil dengan cara pemeriksaan fisik tekanan darah, nadi, dan respirasi diukur menggunakan tensi meter, 
stetoskop, palpasi arteri radialis, serta respirasi dilihat berdasarkan naik turunnya dinding toraks dan pengisian Visual Analogue Scale (VAS). Diberikan terapi musik klasik karya Ludwig Van Beethoven selama prosedur ekstraksi gigi. Data hasil penelitian diolah berdasarkan distribusi frekuensi dan disajikan dalam bentuk Tabel.

\section{HASIL PENELITIAN}

Responden pada penelitian ini adalah pasien yang mendapat terapi musik klasik pada prosedur ekstraksi gigi di RSGM PSPDG-FK UNSRAT pada bulan AgustusSeptember 2015 berjumlah 40 orang dewasa usia 17-65 tahun. Karakteristik responden dapat dilihat pada Tabel 1 distribusi responden penelitian berdasarkan pengalaman menjalani prosedur ekstraksi gigi di RSGM PSPDG-FK Unsrat.

Tabel 1. Distribusi responden penelitian berdasarkan pengalaman menjalani prosedur ektraksi gigi di RSGM PSPDG-FK Unsrat

\begin{tabular}{lcc}
\hline $\begin{array}{l}\text { Pengalaman menjalani } \\
\text { prosedur ekstraksi gigidi RSGM }\end{array}$ & $\mathrm{n}$ & $\%$ \\
\hline PSPDG-FKUNSRAT & 21 & 52,5 \\
\hline Pernah & 19 & 47,5 \\
Belum Pernah & 40 & 100 \\
Total & \\
\hline
\end{tabular}

Tabel 2. Distribusi gambaran kecemasan pasien yang belum pernah menjalani prosedur ekstraksi gigiberdasarkan pengukuran tekanan darah

\begin{tabular}{lcccc}
\hline Kategori & \multicolumn{2}{c}{ TP I } & \multicolumn{2}{c}{ TP II } \\
\cline { 2 - 5 } & $\mathrm{n}$ & $\%$ & $\mathrm{n}$ & $\%$ \\
\hline Tinggi & 8 & 42,11 & 3 & 15,79 \\
Normal & 7 & 36,84 & 15 & 78,95 \\
Rendah & 4 & 21,05 & 1 & 5,26 \\
Total & 19 & 100 & 19 & 100 \\
\hline
\end{tabular}

Tabel 3. Distribusi gambaran kecemasan pasien yang pernah menjalani prosedur ekstraksi gigi berdasarkan pengukuran tekanan darah

\begin{tabular}{ccccc}
\hline \multirow{2}{*}{ Kategori } & \multicolumn{3}{c}{ TP II } \\
\cline { 2 - 5 } & $\mathrm{n}$ & $\%$ & $\mathrm{n}$ & $\%$ \\
\hline Tinggi & 8 & 38,1 & 3 & 14,28 \\
Normal & 10 & 47,62 & 16 & 76,2 \\
Rendah & 3 & 14,28 & 2 & 9,52 \\
Total & 21 & 100 & 21 & 100 \\
\hline
\end{tabular}

Tabel 4. Distribusi gambaran kecemasan pasien yangbelum pernah menjalaniprosedur ekstraksi gigiberdasarkan pengukuran nadi

\begin{tabular}{lcccc}
\hline \multirow{2}{*}{ Kategori } & TP I & TP II & & \\
\cline { 2 - 5 } & $\mathrm{n}$ & $\%$ & $\mathrm{n}$ & $\%$ \\
\hline Tinggi & 14 & 73,68 & 2 & 10,53 \\
Normal & 5 & 26,32 & 17 & 89,47 \\
Rendah & 0 & 0,00 & 0 & 0,00 \\
Total & 19 & 100 & 19 & 100 \\
\hline
\end{tabular}


Mantiri, Opod, Parengkuan: Gambaran kecemasan pasien...

Tabel 5. Distribusi gambaran kecemasan pasien yang pernah menjalani prosedurekstraksi gigi berdasarkan pengukuran nadi

\begin{tabular}{lcccc}
\hline \multirow{2}{*}{ Kategori } & TP I & \multicolumn{2}{c}{ TP II } & \\
\cline { 2 - 5 } & $\mathrm{n}$ & $\%$ & $\mathrm{n}$ & $\%$ \\
\hline Tinggi & 2 & 9,52 & 0 & 0,00 \\
Normal & 19 & 90,48 & 21 & 100 \\
Rendah & 0 & 0,00 & 0 & 0,00 \\
Total & 21 & 100 & 21 & 100 \\
\hline
\end{tabular}

Tabel 6. Distribusi gambaran kecemasan pasien yang belum pernah menjalaniprosedur ekstraksi gigi berdasarkan pengukuran respirasi

\begin{tabular}{lcccc}
\hline \multirow{2}{*}{ Kategori } & \multicolumn{2}{c}{ TP I } & \multicolumn{3}{c}{ TP II } \\
\cline { 2 - 5 } & $\mathrm{n}$ & $\%$ & $\mathrm{n}$ & $\%$ \\
\hline Tinggi & 7 & 36,84 & 3 & 15,79 \\
Normal & 12 & 63,16 & 16 & 84,21 \\
Rendah & 0 & 0,00 & 0 & 0,00 \\
Total & 19 & 100 & 19 & 100 \\
\hline
\end{tabular}

Tabel 7. Distribusi gambaran kecemasan pasien yang pernah menjalani prosedur ekstraksi gigi berdasarkan pengukuran respirasi

\begin{tabular}{lcccc}
\hline \multirow{2}{*}{ Kategori } & \multicolumn{2}{c}{ TP I } & \multicolumn{2}{c}{ TP II } \\
\cline { 2 - 5 } & $\mathrm{n}$ & $\%$ & $\mathrm{n}$ & $\%$ \\
\hline Tinggi & 0 & 0,00 & 0 & 0,00 \\
Normal & 21 & 100 & 21 & 100 \\
Rendah & 0 & 0,00 & 0 & 0,00 \\
Total & 21 & 100 & 21 & 100 \\
\hline
\end{tabular}

Tabel 8. Distribusi gambaran kecemasan pasien yang belum pernah menjalani prosedur ekstraksi gigi berdasarkan pengisian Visual Analogue Scale (VAS)

\begin{tabular}{ccccc}
\hline \multirow{2}{*}{ Skala } & \multicolumn{2}{c}{ TP I } & \multicolumn{2}{c}{ TP II } \\
\cline { 2 - 5 } & $\mathrm{n}$ & $\%$ & $\mathrm{n}$ & $\%$ \\
\hline 1 & 2 & 10,53 & 13 & 68,42 \\
2 & 14 & 73,68 & 5 & 26,32 \\
3 & 2 & 10,53 & 1 & 5,26 \\
4 & 1 & 5,26 & 0 & 0,00 \\
5 & 0 & 0,00 & 0 & 0,00 \\
6 & 0 & 0,00 & 0 & 0,00 \\
Total & 19 & 100 & 19 & 100 \\
\hline
\end{tabular}


Tabel 9. Distribusi gambaran kecemasan pasien yang pernah menjalani prosedur ekstraksi berdasarkan pengisian Visual Analogue Scale (VAS)

\begin{tabular}{cccccc}
\hline \multirow{2}{*}{ Skala } & \multicolumn{2}{c}{ TP I } & \multicolumn{2}{c}{ TP II } \\
\cline { 2 - 6 } & & $\mathrm{n}$ & $\%$ & $\mathrm{n}$ & $\%$ \\
\hline \multirow{2}{*}{ Total } & 8 & 38,1 & 19 & 90,48 \\
& 1 & 12 & 57,14 & 2 & 9,52 \\
& 3 & 1 & 4,76 & 0 & 0,00 \\
& 4 & 0 & 0,00 & 0 & 0,00 \\
& 5 & 0 & 0,00 & 0 & 0,00 \\
& 6 & 0 & 0,00 & 0 & 0,00 \\
& 21 & 100 & 21 & 100 \\
\hline
\end{tabular}

Tabel 10. Distribusi gambaran jumlah pasien yang mengalami penurunan kecemasan yang belum pernah menjalani prosedur ekstraksi gigi berdasarkan pemeriksaan fisik dengan kategori tinggi

\begin{tabular}{|c|c|c|c|c|c|c|}
\hline \multirow[t]{2}{*}{ Kategori } & \multicolumn{2}{|c|}{ TP I } & \multicolumn{2}{|c|}{ TP II } & \multicolumn{2}{|c|}{$\begin{array}{l}\text { Jumlah yangmengalami } \\
\text { penurunan kecemasan }\end{array}$} \\
\hline & $\mathrm{n}$ & $\%$ & & $\%$ & $\mathrm{n}$ & $\%$ \\
\hline Tekanan Darah & 8 & 42,11 & 3 & 15,79 & 5 & 26,32 \\
\hline Nadi & 14 & 73,68 & 2 & 10,53 & 12 & 63,15 \\
\hline Respirasi & 7 & 36,84 & 3 & 15,79 & 4 & 21,05 \\
\hline Rata-rata & & & & & & 36,84 \\
\hline
\end{tabular}

Tabel 11. Distribusi gambaran jumlah pasien yang mengalami penurunan kecemasanyangpernah menjalani prosedur ekstraksi gigi berdasarkan pemeriksaan fisikdengan kategori tinggi.

\begin{tabular}{lrrrrrr}
\hline \multirow{2}{*}{ Kategori } & \multicolumn{2}{c}{ TP I } & & \multicolumn{2}{c}{ TP II } & \multicolumn{2}{c}{$\begin{array}{c}\text { Jumlah yang mengalami } \\
\text { penurunan kecemasan }\end{array}$} \\
\cline { 2 - 7 } & $\mathrm{n}$ & \multicolumn{1}{c}{$\%$} & $\mathrm{n}$ & \multicolumn{1}{c}{$\%$} & $\mathrm{n}$ & $\%$ \\
\hline Tekanan Darah & & & & & & \\
Nadi & 8 & 38,10 & 3 & 14,28 & 5 & 23,82 \\
Respirasi & 2 & 9,52 & 0 & 0,00 & 2 & 9,52 \\
Rata-rata & 0 & 0,00 & 0 & 0,00 & 0 & 0,00 \\
\hline
\end{tabular}

\section{BAHASAN}

Hasil dari Tabel 2 pengukuran tekanan darah pada pasien yang belum pernah menjalani ekstraksi gigi menunjukkan kecemasan pada tahap pemeriksaan pertama (TP I) saat pre-ekstraksi gigi tanpa terapi musik klasik sejumlah 42,11\% pasien, namun sejumlah 15,79\% pasien (TP II) mengalami penurunan tekanan darah setelah terapi musik klasik, dan data pasien yang sebelumnya pernah menjalani prosedur ekstraksi gigi berdasarkan pengukuran tekanan darah di Tabel 3 menunjukkan bahwa kecemasan saat tindakan ekstraksi gigi akan dilakukan yakni pada sejumlah $38,1 \%$ pasien (TP I), dan mengalami penurunan sejumlah 14,28\% pasien (TP II) setelah terapi musik klasik. Permatasari (2013) ${ }^{7}$ meneliti bahwa ada hubungan positif yang signifikan antara kecemasan dental dengan perubahan tekanan darah sebelum dilakukan 
pencabutan gigi, dan pada pasien yang pernah menjalani ekstraksi gigi sebelumnya tidak bisa menjamin indikator menurunnya kecemasan seseorang pada prosedur ekstraksi gigi yang akan dilakukan selanjutnya. Pengalaman yang tidak menyenangkan membuat pasien trauma dan menjadi penyebab utama rasa cemas, misalnya tingkah laku seorang dokter gigi yang menangani pasien dalam tindakan ekstraksi gigi, dan rasa sakit yang dialami pasien saat tindakan ekstraksi gigi sebelumnya dilakukan. ${ }^{8}$ Sebuah studi di Belanda yang dikutip oleh Blinkhorn dan Kent, ${ }^{9}$ melaporkan bahwa hanya $14 \%$ dari penduduk Belanda tidak mengalami kecemasan, sementara hampir 65\% mengalami kecemasan ketika mengunjungi dokter gigi setelah perawatan sebelumnya.

Tabel 4 mengenai hasil pengukuran nadi menunjukkan kecemasan pasien yang belum pernah menjalani prosedur ekstraksi gigi terdapat pada TP I yakni sejumlah $73,68 \%$ pasien. Keadaan ini mengindikasi bahwa prosedur ekstraksi gigi menyebabkan kecemasan pada sejumlah pasien. Persepsi akan nyeri biasanya jadi pemicu utama kecemasan pasien dalam melakukan ekstraksi gigi, hal ini terjadi karena kurangnya pemahaman pasien mengenai prosedur yang akan dijalani. ${ }^{6}$ Beatrix (2014), meneliti bahwa ada hubungan tingkat kecemasan dengan perubahan denyut nadi pada pasien ekstraksi gigi, bahwa terjadinya peningkatan denyut nadi karena ada ketakutan dalam diri pasien dengan peralatan ekstraksi gigi dan resiko yang akan terjadi saat ekstraksi gigi dilakukan. ${ }^{10}$ Sesuai hasil penelitian dimana terjadi penurunan kecemasan sejumlah 10,53\% pasien pada TP II post-ekstraksi gigi saat pasien telah mendapat terapi musik klasik, sebab musik klasik dapat mempengaruhi kontraksi dan efek relaksasi organ-organ sehingga menimbulkan perasaan tenang pada pasien. ${ }^{8}$

Tabel 5 menunjukkan pada dua tahap pemeriksaan nadi pada pasien yang pernah menjalani prosedur ekstraksi gigi hasilnya tertinggi pada kategori normal baik TP I maupun TP II. Ini menunjukkan kunjungan rutin ke dokter gigi bisa menurunkan kecemasan, demikian pula yang dialami pasien yang sudah pernah atau telah berkali-kali menjalani prosedur ekstraksi gigi.

Tabel 6 menunjukkan kecemasan pasien yang belum pernah menjalani prosedur ekstraksi gigi dari hasil pengukuran respirasi pada TP I sejumlah 36,84\% pasien. Sementara, hasil pada TP II post-ekstraksi gigi setelah pasien mendapat terapi musik klasik, kecemasan lewat pengukuran respirasi turun sejumlah $15,79 \%$ pasien.

Tabel 7 pengukuran respirasi pada pasien yang pernah menjalani prosedur ekstraksi gigi pada dua tahap pemeriksaan yaitu tidak ada pasien yang dikategorikan cemas.

Pengukuran berdasarkan VAS di Tabel 8 pasien yang belum pernah menjalani prosedur ekstraksi gigi menunjukkan kecemasan tertinggi pada TP I sejumlah 73,68\% dengan kategori sedikit cemas, dan setelah pasien mendapat terapi musik klasik pada TP II penurunan kecemasan terjadi sejumlah 26,32\%. Adapun pada pasien dengan kategori tidak menyenangkan sejumlah 10,53\%, pada TP II terjadi penurunan sejumlah 5,26\%, pasien pada kategori meenyedihkan sejumlah 5,26\% dan pada TP II tidak ada pasien pada kategori menyedihkan.

Sesuai dengan hasil observasi dan wawancara bahwa pasien yang belum pernah menjalani prosedur ekstraksi gigi pada TP I dan TP II bahwa, terapi musik klasik memberi efek relaksasi untuk pasien yang cemas, sehingga pada saat prosedur ekstraksi gigi dilakukan sampai selesai skala VAS yang dinilai berdasarkan perasaan pasien sendiri mengalami perubahan yang tadinya raut wajah yang diisi yaitu sedikit cemas (skala 2) sampai menyedihkan (skala 4) perlahan skala VAS mengalami perubahan menjadi tidak cemas (skala 1). Hasil yang diperoleh sesuai dengan penelitian Setiawan AS et $\mathrm{al}^{8}{ }^{8}$ menunjukkan bahwa penggunaan musik Mozart dalam perawatan kedokteran gigi bagi pasien anak yang berkunjung di Klinik 
Kedokteran Gigi Anak RSGM UNPAD menurunkan kecemasan sejumlah 76,67\% setelah mendengar musik.

Pada Tabel 9 penggunaan terapi musik klasik pada pasien yang sudah pernah menjalani tindakan ekstraksi gigi pengukuran berdasarkan VAS, menunjukkan bahwa dari 57,14\% pasien dengan kategori sedikit cemas dan penurunan kecemasan terjadi pada saat pasien telah mendapatkan terapi musik klasik pada TP II sejumlah 9,52\% pasien, pada kategori tidak menyenangkan sejumlah $4,76 \%$ pasien dan hasil pada TP II menjadi tidak ada pasien pada kategori tidak menyenangkan. Hasil observasi dan wawancara pada pasien yang pernah menjalani prosedur ekstraksi gigi pada TP I dan TP II bahwa, terapi musik klasik memberi ketenangan untuk pasien yang cemas dan terbukti pada skala VAS yang dinilai berdasarkan perasaan yang dialami sendiri oleh pasien mengalami perubahan.

Pada Tabel 10 distribusi gambaran penurunan kecemasan pasien yang belum pernah menjalani prosedur ekstraksi gigi berdasarkan pemeriksaan fisik dengan kategori tinggi dengan rata-rata pada tiga tahap pemeriksaan sejumlah $36,84 \%$. Pada Tabel 11 distribusi gambaran penurunan kecemasan pasien yang pernah menjalani prosedur ekstraksi gigi rata-rata sejumlah 11,11\%. Campbell (2001) ${ }^{5}$ menjelaskah bahwa musik klasik dapat menyeimbangkan gelombang otak dan musik dengan tempo dan irama yang lembut seperti halnya musik klasik memiliki beberapa manfaat, yaitu menutupi bunyi dan perasaan tidak menyenangkan, memengaruhi perasaan, mempengaruhi denyut nadi, denyut jantung, tekanan darah, respirasi dan mengatur suhu badan, mengurangi ketegangan otot dan memperbaiki gerak serta koordinasi tubuh, mengatur hormonhormon yang berkaitan tentang stres, dan musik dapat menimbulkan rasa aman.

\section{SIMPULAN}

Penggunaan terapi musik klasik pada prosedur ekstraksi gigi di RSGM PSPDGFK UNSRAT mampu menurunkan kecemasan pasien. Penggunaan terapi musik klasik pada prosedur ekstraksi gigi mampu menurunkan kecemasan pasien yang belum pernah menjalani ekstraksi gigi dari hasil pengukuran fisik tekanan darah, nadi, dan respirasi dengan hasil rata-rata sebesar 36,84\%, sedangkan pasien yang sudah pernah menjalani prosedur ekstraksi gigi sebesar $11,11 \%$.

Penggunaan terapi musik klasik pada prosedur ekstraksi gigi dari hasil pengukuran Visual Analogue Scale (VAS) mampu menurunkan kecemasan pasien yang belum pernah menjalani prosedur ekstraksi gigi sejumlah 26,32\% pasien kategori sedikit cemas, sejumlah 5,26\% pasien kategori tidak menyenangkan, dan tidak ada pasien pada kategori menyedihkan dan yang pernah menjalani prosedur ekstraksi gigi sejumlah 9,52\% pasien kategori sedikit cemas.

\section{SARAN}

Penelitian lebih lanjut dapat dilakukan untuk menilai efektifitas penggunaan musik klasik terhadap kecemasan pasien yang menjalani prosedur ekstraksi gigi, yang kemudian dikaitkan dengan umur, latar belakang suku, jenis kelamin, dan jenis musik favorit. Terapi musik klasik dapat dipertimbangkan penggunaanya di RSGM PSPDG-FK Unsrat sebagai sarana alternatif dalam mengatasi kecemasan pasien yang menjalani prosedur ekstraksi gigi maupun perawatan gigi lainnya.

\section{UCAPAN TERIMAKASIH}

Ucapan terimakasih disampaikan kepada drg. Michael A. Leman, MMedEd, drg. Bernart S. P Hutagalung, M.Kes dan semua pihak baik secara langsung maupun tidak langsung yang telah membuahkan ide atau gagasan dalam pemikiran penulis sehingga dapat menyelesaikan artikel ini

\section{DAFTAR PUSTAKA}

1. Laporan Riset Kesehatan Dasar Nasional 2001. Jakarta: Badan penelitianDan pengembangan kesehatan kementrian kesehatan RI [serial online]. 2013 [cited 2015 March]; p.135-140. 
Available from: www.litbang.depkes.go.id.

2. Pedersen GW. Buku ajar praktis bedah mulut. Alih bahasa: Purwanto, Basoeseno. Jakarta: EGC, 1996; p. 29-36,101-3,117-8.

3. Tangkere H. Gambaran kecemasan pasien saat menjalani prosedur ekstraksi gigi sambil mendengarkan musik Mozart di puskesmas. Jurnal e-Gigi. 2013;1:69-78.

4. Laila FA, Ristiana MS. Perbedaan efektivitas penggunaan teknik distraksi (musik klasik) dan relaksasi (nafas dalam) terhadap penurunan tingkat kecemasan pada pasien dengan perawatan luka post fraktur ekstremitas bawah di RSUD Kota dan Kabupaten Pekalongan. [serial online]. 2012 [cited March 2015]. Available from: http://www.eskripsi.stikesmuhpkj.ac.id/eskripsi/index.php?p=fstrea m-pdf\&fid=199\&bid=246

5. Campbell. Efek Mozart. Alih bahasa: Hermaya T. Jakarta: Gramedia, 2001; p. 82

6. Moola S. Effectiveness of music interventions in reducing dental anxiety in pediatric and adult patients [Thesis]. The Joanna Briggs Institute:

University of Adelaide; [serial online] 2011. [cited April 2015]. Available from:

http://connect.jbiconnectplus.org/Vie wSourceFile.aspx?0=7113.Accesed

7. Resya P. Hubungan kecemasan dengan perubahan tekanan darah pasien ekstraksi gigi di Rumah Sakit Gigi dan Mulut Pendidikan (RSGMP) HJ. Halimah DG. Sikati Makasar. [serial online] 2013. [cited April 2015]. Available from: http://repository.unhas.ac.id/bitstream /handle/123456789/8239/Resya\%20P ermatasari\%20\%20J111\%2010\%20150.pdf?sequenc $\mathrm{e}=1$

8. Setiawan AS, Zidnia H, Sasmita IS. Mozart effect on dental anxiety in 612 year old children. Dent J. 2010;43(1):17-20.

9. Blinkhorn AS, Kent GG. Pengelola tingkah laku pasien pada praktik dokter gigi (2 ed). Jakarta: EGC; 2005.

10. Pontoh B, Pangemanan DHC, Mariati NW. Hubungan tingkat kecemasan dengan perubahan denyut nadi pada pasien ekstraksi gigi di Puskesmas Tuminting Manado. Jurnal e-Gigi. 2015:3:13-7. 